\title{
Brain-to-Brain Paradoxical Embolism through Patent Foramen Ovale after Cerebral Vein Thrombosis
}

\author{
Massimo Del Sette Lavinia Dinia Carlo Gandolfo \\ Department of Neurosciences, Ophthalmology and Genetics, University of Genova, Genova, Italy
}

Dear Sir,

Patients with right-to-left shunt due to patent foramen ovale (PFO), especially if associated to atrial septal aneurysm, are at increased risk of stroke [1-5]. Although there are many possible mechanisms of stroke in these subjects (in situ formation of thrombus, atrial vulnerability, other comorbidities), paradoxical embolism is thought to be one of the most important causes of stroke, yet difficult to be proven [6-8]. Ultrasonographic examination of the venous system as well as CT or MRA studies can identify a venous source in no more than $20 \%$ of subjects with cryptogenic stroke [7-10].

We report a case of stroke in a young man with a large PFO, in which the only source of paradoxical embolism was the presence of a recent cerebral venous thrombosis.

\section{Case Report}

We investigated a right-handed 50year-old man, admitted to our Stroke Unit in June 2004, for headache, dizziness and delirium, followed by mild left hemiparesis. MRI and MRA showed the presence of venous thrombosis of sagittal sinus and right transverse and sigmoid sinuses, without parenchymal brain lesions. Screening for thrombophilia did not show any abnormality. The patient had been diagnosed 4 years before as having a non-Hodgkin lymphoma and had undergone bone marrow transplantation 3 years before. He was at that time in therapy with cyclosporine. No hematologic abnormalities, nor hyperhomocysteine, nor genetic mutations of co- agulation factors were found; in particular, we searched for MTHFR mutation, prothrombin G20210A mutation and factor $\mathrm{V}$ Leyden mutation, and none was found. He was treated with intravenous heparin (5,000 IU bolus, followed by continuous infusion of 1,000 IU/h), with complete resolution of symptoms. Color-coded duplex sonography of the cervical arteries showed no carotid or vertebral disease, and arterial transcranial Doppler ultrasound was unremarkable. A venous color-Doppler of the legs did not show the presence of venous thrombosis, yet it cannot completely exclude this condition. A second cerebral MRI and MRA examination showed partial recanalization of transverse and sigmoid sinuses, and the persistence of thrombosis of sagittal sinus. Then the patient was discharged with oral anticoagulants (warfarin) with a suggested International Normalized Ratio interval of 2-3.

After 10 months, warfarin was stopped and replaced with aspirin, $100 \mathrm{mg}$, because of the occurrence of bilateral spontaneous subdural hematoma.

Two months later he was admitted again to our Stroke Unit for sudden onset of vertigo, nausea, vomiting and cerebellar ataxia. Neurological examination showed horizontal nystagmus and dysmetria of the right limbs. The acute cerebral CT scan was normal, while a CT scan, performed after $48 \mathrm{~h}$, showed a right cerebellar infarction with mass effect. MRI confirmed the presence of the recent right cerebellar ischemic infarction, associated with other recent bilateral temporal and occipital small areas of arterial ischemia, with neuroradiological characteristics of possible small embolic lesions. Moreover, MRA showed slow flow in the left tranverse sinus, suggesting a recent episode of cerebral venous thrombosis. A traditional digital subtraction angiography showed no arterial lesions, but confirmed slow flow, expression of recent venous thrombosis, in the left transverse sinus, previously patent. Thrombolytic therapy was not performed because of the clinical history and because of the long time interval from onset $(>5 \mathrm{~h})$. To identify the cause of the ischemic stroke in the still young patient, a transcranial Doppler with gaseous contrast was done, and a large right-to-left shunt was demonstrated, with 9 microbubbles at rest and curtain effect during Valsalva maneuver $[11,12]$. Then a transesophageal echocardiography confirmed the presence of a large PFO without atrial septal aneurysm. The clinical workup (venous Duplex of legs, abdominal echography, total body CT scan with contrast medium, MRA of pelvic veins) failed to show venous sources of paradoxical embolism other than the thrombus in the left transverse sinus. During his stay in our Stroke Unit, the patient was monitored as usual, and continuous ECG did not show atrial fibrillation or other potentially emboligenic dysrhythmia. The patient got better, and he was discharged with a mild right ataxic syndrome, with oral anticoagulant therapy. Then the opportunity to undergo transcatheter closure of the PFO was discussed with the patient.

\section{KARGER}

Fax +41613061234 E-Mail karger@karger.ch www.karger.com
(C) 2007 S. Karger AG, Basel 0014-3022/07/0573-0176\$23.50/0

Accessible online at: www.karger.com/ene
Massimo Del Sette, MD

Department of Neurosciences, Ophthalmology and Genetics, University of Genova Via De Toni 5

IT-16132 Genova (Italy)

Tel. +39 010353 7066, Fax +39010 353 8625, E-Mail mdelsette@neurologia.unige.it 


\section{Discussion}

PFO can be the cause of stroke when it occurs in young subjects without other clear cause of stroke [1-5]. Nevertheless, a venous source of emboli is not often found [6-8]. A recent MRI study reported the presence of thrombosis of pelvic veins in $20 \%$ of subjects with cryptogenic stroke and PFO [9].

Cerebral venous thrombosis can be due to local flogistic factors as well as to thrombophilic conditions. In our case the original cerebral vein thrombosis was thought to be caused by thrombophylic state due to non-Hodgkin lymphoma or to cyclosporine therapy [13-18]. The possibility of an intravascular lymphomatosis was excluded by the value of circulating white blood cells, which was normal, and by the clinical course [19].

As the patient had subdural hematomas, warfarin was stopped after the first episode of cerebral vein thrombosis, and probably the thrombotic process in the cerebral vein restarted, facilitated by the venous stasis due to the incomplete recanalization of the first episode. This was probably the mechanism of the last paradoxical embolic event.

Patients with cryptogenic stroke and PFO have high probability to be affected by coagulopathies and venous thrombosis [20-25]. Moreover, the presence of coagulopathies does not obviate the search for venous thrombosis [8]. Lethen et al. [7], studying with phlebography 53 patients with stroke or transient ischemic attack due to $\mathrm{PFO}$, found the presence of deep vein thrombosis in 9.5\%. Cramer et al. [9] reported pelvic vein thrombosis in $20 \%$ of patients with cryptogenic stroke. In our case, the patient had neither coagulopaties nor mutation of coagulation factors, and the intravascular pathology was the cause of cerebral venous thrombosis. Valdueza et al. [26] reported presence of microemboli in the jugular vein in 3 out of 6 subjects with sagittal sinus thrombosis. We did not search for microemboli in the jugular veins, but Duplex showed bilateral patency of the veins. In our case, the presence of PFO was the cause of paradoxical embolization from the cerebral veins to the brain.

\section{References}

1 Webster MW, Chancellor AM, Smith HJ, et al: Patent foramen ovale in young stroke patients. Lancet 1988;2:11-12.

2 Lechat P, Mas JL, Lascault G, et al: Prevalence of patent foramen ovale in patients with stroke. N Engl J Med 1988;318:11481152.

3 Steiner MM, Di Tullio MR, Rundek T, et al: Patent foramen ovale size and embolic brain imaging findings among patients with ischemic stroke. Stroke 1998;29:944-948.

4 Orgera MA, O’Malley PG, Taylor AJ: Secondary prevention of cerebral ischemia in patent foramen ovale: systematic review and meta-analysis. South Med J 2001;94:699703.

5 Cabanes L, Mas JL, Cohen A, et al: Atrial septal aneurysm and patent foramen ovale as risk factors for cryptogenic stroke in patients less than 55 years of age: a study using transesophageal echocardiography. Stroke 1993; 24:1865-1873.

6 Evans AJ, Sostman HD, Knelson MH, et al: 1992 ARRS Executive Council Award: detection of deep venous thrombosis - prospective comparison of MR imaging with contrast venography. AJR Am J Roentgenol 1993;161:131-139.

7 Lethen H, Flachskampf FA, Schneider R, et al: Frequency of deep vein thrombosis in patients with patent foramen ovale and ischemic stroke or transient ischemic attack. Am J Cardiol 1997;80:1066-1069.

8 Stollberger C, Finsterer J: Search for coagulopathy does not obviate search for venous thrombosis in suspected paradoxical embolism. Stroke 2003;34:e146-e147.

9 Cramer SC, Rordorf G, Maki JH, et al: Increased pelvic vein thrombi in cryptogenic stroke: results of the Paradoxical Emboli from Large Veins in Ischemic Stroke (PELVIS) study. Stroke 2004;35:46-50.
10 Carpenter JP, Holland GA, Baum RA, Owen RS, Carpenter JT, Cope C: Magnetic resonance venography for the detection of deep venous thrombosis: comparison with contrast venography and duplex Doppler ultrasonography. J Vasc Surg 1993;18:734-741.

11 Jauss M, Zanette E: Detection of right-to-left shunt with ultrasound contrast agent and transcranial Doppler sonography. Cerebrovasc Dis 2000;10:490-496.

12 Angeli S, Del Sette M, Beelke M, et al: Transcranial Doppler in the diagnosis of cardiac patent foramen ovale. Neurol Sci 2001;22: 353-356.

13 Caocci G, Fenu L, La Nasa G, Marongiu F: Superior sagittal sinus thrombosis after lumbar puncture in a patient with T-cell lymphoblastic lymphoma: role of the prothrombin G20210A mutation and 4G/4G genotype. Thromb Haemost 2005;94:881-882.

14 Matsumoto K, Ohta M, Takeshita I: Reversible non-thrombotic occlusion of the superior sagittal sinus caused by metastatic malignant lymphoma - case report. Neurol Med Chir (Tokyo) 2003;43:349-351.

15 Al-Shekhlee A, Oghlakian G, Katirji B: A case of cyclosporine-induced dural sinus thrombosis. J Thromb Haemost 2005;3: 1327-1328.

16 Bertz H, Laubenberger J, Steinfurth G, Finke $\mathrm{J}$ : Sinus venous thrombosis: an unusual cause for neurologic symptoms after bone marrow transplantation under immunosuppression. Transplantation 1998;66:241-244.

17 Harvey CJ, Peniket AJ, Miszkiel K, et al: MR angiographic diagnosis of cerebral venous sinus thrombosis following allogeneic bone marrow transplantation. Bone Marrow Transplant 2000;25:791-795.

18 Wada H, Sase T, Yamaguchi M: Hypercoagulant states in malignant lymphoma. Exp Oncol 2005;27:179-185.
19 Kenez J, Barsi P, Majtenyi K, et al: Can intravascular lymphomatosis mimic sinus thrombosis? A case report with 8 months' followup and fatal outcome. Neuroradiology 2000; 42:436-440.

20 Rodriguez CJ, Homma S: Hypercoagulable states in patients with patent foramen ovale. Curr Hematol Rep 2003;2:435-441.

21 Karttunen V, Hiltunen L, Rasi V, Vahtera E, Hillbom M: Factor V Leiden and prothrombin gene mutation may predispose to paradoxical embolism in subjects with patent foramen ovale. Blood Coagul Fibrinolysis 2003; 14:261-268.

22 Chaturvedi S: Coagulation abnormalities in adults with cryptogenic stroke and patent foramen ovale. J Neurol Sci 1998;160:158160.

23 Nagano K, Otsubo R, Yasaka M, et al: Stroke recurrence in patients with brain embolism and patent foramen ovale - association with deep vein thrombosis detected by ultrasonography. Rinsho Shinkeigaku 2004;44:713.

24 Lichy C, Reuner KH, Buggle F, et al: Prothrombin G20210A mutation, but not factor $\mathrm{V}$ Leiden, is a risk factor in patients with persistent foramen ovale and otherwise unexplained cerebral ischemia. Cerebrovasc Dis 2003;16:83-87.

25 Pezzini A, Del Zotto E, Magoni M, et al: Inherited thrombophilic disorders in young adults with ischemic stroke and patent foramen ovale. Stroke 2003;34:28-33.

26 Valdueza JM, Harms L, Doepp F, et al: Venous Microembolic signals detected in patients with cerebral sinus thrombosis. Stroke 1997;28:1607-1609. 